BMJ

Open

Gastroenterology

\section{Association between antidepressant medication use and steroid dependency in patients with ulcerative colitis: a population-based study}

To cite: Blackwell J, Alexakis C, Saxena S, et al. Association between antidepressant medication use and steroid dependency in patients with ulcerative colitis: a populationbased study. BMJ Open Gastro 2021;8:e00588. doi:10.1136/ bmjgast-2020-000588

$\mathrm{JB}$ and CA contributed equally

$\mathrm{JB}$ and $\mathrm{CA}$ are joint first authors.

Received 14 December 2020 Revised 22 February 2021 Accepted 24 February 2021

Check for updates

(c) Author(s) (or their employer(s)) 2021. Re-use permitted under CC BY. Published by BMJ.

For numbered affiliations see end of article.

Correspondence to Dr Jonathan Blackwell; j.blackwell@imperial.ac.uk

\section{ABSTRACT}

Background Animal studies indicate a potential protective role of antidepressant medication (ADM) in models of colitis but the effect of their use in humans with ulcerative colitis (UC) remains unclear.

Objective To study the relationship between ADM use and corticosteroid dependency in UC.

Design Using the Clinical Practice Research Datalink we identified patients diagnosed with UC between 2005 and 2016. We grouped patients according to serotonin selective reuptake inhibitor (SSRI) and tricyclic antidepressant (TCA) exposure in the 3 years following diagnosis: 'continuous users', 'intermittent users' and 'non-users'. We used logistic regression to estimate the adjusted risk of corticosteroid dependency between ADM exposure groups.

Results We identified 6373 patients with UC. Five thousand two hundred and thirty (82\%) use no ADMs, 627 $(10 \%)$ were intermittent SSRI users and $282(4 \%)$ were continuous SSRI users, 246 (4\%) were intermittent TCA users and $63(1 \%)$ were continuous TCA users. Corticosteroid dependency was more frequent in continuous SSRI and TCA users compared with nonusers ( $19 \%$ vs $24 \%$ vs $14 \%$, respectively, $\chi^{2} p=0.002$ ). Intermittent SSRI and TCA users had similar risks of developing corticosteroid dependency to non-users (SSRI: OR $1.19,95 \%$ Cl 0.95 to 1.50 , TCA: OR $1.14,95 \%$ Cl 0.78 to 1.66). Continuous users of both SSRIs and TCAs had significantly higher risks of corticosteroid dependency compared with non-users (SSRI: OR 1.62, 95\% Cl 1.15 to 2.27, TCA: OR 2.02, 95\% Cl 1.07 to 3.81).

Conclusions Continuous ADM exposure has no protective effect in routine clinical practice in UC and identifies a population of patients requiring more intensive medical therapy. ADM use is a flag for potentially worse clinical outcomes in UC.

\section{INTRODUCTION}

Antidepressant medications (ADMs) may have a role in reducing intestinal inflammation. ${ }^{1}$ However, the benefits of pharmacological treatment with ADMs in patients with inflammatory bowel disease (IBD) are poorly
Summary box

What is already known about this subject?

- Antidepressant medications (ADMs) are used frequently in the inflammatory bowel disease population. Animal studies have demonstrated a potential role of antidepressants to ameliorate inflammation in colitis. One study of people living with ulcerative colitis (UC) suggested steroid requirements were lower during periods of ADM use. However, other studies demonstrate comorbid anxiety and depression are associated with worse outcomes in UC. It is unclear where the balance of these factors lies with respect to ADM use in routine clinical practice in UC.

What are the new findings?

- This study found that continuous use of serotonin selective reuptake inhibitors (SSRIs) and tricyclic antidepressants (TCA) were both associated with a significant increase in the risk of corticosteroid dependency compared with non-users (SSRI: OR 1.62, $95 \% \mathrm{Cl} 1.15$ to 2.27 , TCA: OR $2.02,95 \% \mathrm{Cl} 1.07$ to 3.81).

How might it impact on clinical practice in the foreseeable future?

- Continuous ADM exposure in routine clinical practice in UC identifies a population of patients requiring more intensive medical therapy and is a flag for potentially worse clinical outcomes in UC.

researched. Evidence from animal models of IBD indicate that ADMs can reduce intestinal inflammation via modulation of neurohumoral pathways. ${ }^{2-5}$ However, studies in humans are conflicting regarding any benefit of $\mathrm{ADM}$ on disease outcomes in IBD. ${ }^{6-10} \mathrm{~A}$ Cochrane review found no firm conclusions regarding the effects of ADMs in IBD could be drawn and further studies are required. ${ }^{11}$

A two-way relationship between psychological stress and disease activity in ulcerative colitis (UC) is likely. ${ }^{12}$ It is hypothesised that 
activation of the sympathetic autonomic nervous system due to stress leads to secretion of epinephrine and norepinephrine, which has been linked to activation of macrophages and mast cells, which may in turn increase bacterial adherence to gut mucosa. ${ }^{13} 14$ Furthermore, stress activates the hypothalamic pituitary adrenal axis, which can result in increased gut permeability and levels of glucocorticoids, which if prolonged may desensitise glucocorticoid receptors, paradoxically leading to a proinflammatory state. ${ }^{15-17}$ Conversely, patients with IBD have significantly higher prevalence of mood disorders and use of ADMs than matched controls, ${ }^{18-21}$ but it remains unclear what impact these drugs may have on disease activity when used in routine clinical practice. While these drugs may ameliorate gut inflammation through neuro-humoral pathways it is also possible their use to treat comorbid mood disorders maybe associated with poorer outcomes in IBD. It is known comorbid depression and anxiety are associated with unfavourable outcomes, not least increased mortality, for many chronic diseases including IBDs. ${ }^{22-26}$

In order to determine the balance of these factors, we therefore aimed to study the relationship between $\mathrm{ADM}$ use and disease activity, as evidenced by corticosteroid dependency as previously defined by the British Society of Gastroenterology and the European Crohn's and Colitis organisation, using a previously characterised cohort of patients with UC from a nationally representative research database. ${ }^{27-29}$

\section{METHODS}

\section{Study design and data source}

Using the Clinical Practice Research Datalink (CPRD) we undertook a study of patients diagnosed with UC in the period 2005-2016. CPRD is among the largest and best validated primary care research databases worldwide. It contains prospectively collected, patient-level, pseudonymised electronic health records derived from 674 general practices and is representative of the UK population, covering $8 \%$ of the population. ${ }^{30}$ General practitioners use a clinical coding system (Read codes) to record diagnoses, symptoms and prescriptions, as part of routine clinical care. Data are audited to ensure accuracy and completeness. Participating practices need to achieve and maintain 'up to standard' (UTS) status to continue contributing to the dataset. CPRD has been extensively validated for population-based studies of both IBD and ADM use. ${ }^{31} 32$

\section{Incident case definition}

We defined incident UC cases as patients with a first ever diagnosis Read code for UC at least 1 year after registering with an 'UTS' practice for the period 1 January 2005 to 31 December 2016 using a published and validated methodology by Lewis $e t \mathrm{al}^{31}{ }^{31}$ We excluded patients if they had codes for both Crohn's disease (CD) and UC, or indeterminate codes (eg, 'non-specific colitis').
Patients who had a comorbid condition other than UC that might require regular or prolonged steroid use, such as patients with polymyalgia rheumatic and asthma, were also excluded to avoid potential confounding for our primary outcome measure. Patients with previous organ transplants were also excluded because of the likely use of concurrent immunosuppressant and steroid medications in this group. Patients were followed up for 3 years after the date of UC diagnosis until study end-point, de-registration, or death.

We extracted data for the most commonly prescribed tricyclic antidepressants (TCAs) and serotonin selective reuptake inhibitors (SSRIs) during the study period: amitriptyline, dosulepin, escitalopram, sertraline, citalopram, fluoxetine and paroxetine. ${ }^{33}$ In a preliminary analysis, we identified $170000 \mathrm{ADM}$ prescriptions among patients with IBD and calculated that the median ADM prescription length was 30 days (IQR 28-56). For the purposes of this study, we assumed that all ADM prescriptions were 30 days in length.

We categorised individuals according to TCA and SSRI use. We adapted previously validated methods to define patients who were 'continuous users', namely those with repeat prescriptions with a gap of no greater than 60 days between consecutive prescriptions in the first 3 years after UC diagnosis. ${ }^{34}$ We defined 'intermittent users', as patients who had at least one prescription of a TCA or SSRI in the first 3 years following UC diagnosis, but were not 'continuous users'. Our comparator group was 'nonusers'; patients who had no prescriptions for ADMs in the first 3 years after diagnosis of UC.

\section{Outcome measure}

We determined the proportion of patients who developed corticosteroid dependency since it is associated with poorer outcomes in patients with UC. ${ }^{35}$ We used the European Crohn's and Colitis Organisation and British Society of Gastroenterology guidelines criteria to identify patients with corticosteroid dependency. ${ }^{28}{ }^{36}$ A patient was defined as 'corticosteroid dependent' if they had either a prescription for corticosteroids that lasted longer than 3 months or required a repeat corticosteroid prescription within 3 months of stopping the previous corticosteroid course. We assumed that a corticosteroid course was 56 days long as British Society of Gastroenterology guidance recommends a $6-8$ weeks course and a recent UK wide survey has found $>98 \%$ of prescribers taper corticosteroids over 8 weeks in $\mathrm{UC}^{28}$

\section{Covariates}

We included covariates with known or likely associations with TCA and SSRI use and CS dependence. These comprised: sex, age category at UC diagnosis and era of UC diagnosis.

Younger age at diagnosis may be associated with poorer outcomes in UC including increased steroid use compared with older patient groups. ${ }^{37}$ Patients were subdivided into 
Table 1 Baseline characteristics of ulcerative colitis patients by SSRI exposure status

\begin{tabular}{|c|c|c|c|}
\hline & $\begin{array}{l}\text { SSRI } \\
\text { non-users* } \\
n=5464\end{array}$ & $\begin{array}{l}\text { SSRI } \\
\text { intermittent } \\
\text { users }^{\star} n=627\end{array}$ & $\begin{array}{l}\text { SSRI } \\
\text { continuous } \\
\text { users }^{\star} n=282\end{array}$ \\
\hline Male sex & $3091(57 \%)$ & $270(43 \%)$ & $128(45 \%)$ \\
\hline \multicolumn{4}{|c|}{ Age at diagnosis } \\
\hline$<17$ years & $199(4 \%)$ & $1(0 \%)$ & $0(0 \%)$ \\
\hline 17-40years & 1599 (29\%) & 203 (33\%) & 82 (29\%) \\
\hline$>40$ years & $3666(67 \%)$ & $419(67 \%)$ & 200 (71\%) \\
\hline \multicolumn{4}{|l|}{ Era of diagnosis } \\
\hline 2005-2008 & $2561(47 \%)$ & 269 (43\%) & 105 (37\%) \\
\hline 2009-2012 & 2117 (39\%) & 264 (42\%) & $118(42 \%)$ \\
\hline 2013-2016 & $786(14 \%)$ & $94(15 \%)$ & $59(21 \%)$ \\
\hline Smoker & $431(8 \%)$ & 85 (14\%) & 36 (13\%) \\
\hline \multicolumn{4}{|c|}{ Tricyclic ADM use } \\
\hline Non-users & 5230 (96\%) & 566 (90\%) & 268 (95\%) \\
\hline $\begin{array}{l}\text { Intermittent } \\
\text { users }\end{array}$ & $190(4 \%)$ & $50(8 \%)$ & $6(2 \%)$ \\
\hline $\begin{array}{l}\text { Continuous } \\
\text { users }\end{array}$ & 44 (1\%) & $11(2 \%)$ & $8(3 \%)$ \\
\hline
\end{tabular}

${ }^{*}$ Non-users defined as patients with no SSRI prescriptions in first 3 years of diagnosis.

tIntermittent users defined as patients who received at least one SSRI prescription within the first 3 years of diagnosis but were not continuous users.

¥Continuous users defined as patients with consecutive SSRI prescriptions for first 3 years after diagnosis where the interval between SSRI prescription $<90$ days.

ADM, antidepressant medication; SSRI, serotonin selective reuptake inhibitor.

three groups denoting their age at diagnosis $(<17,17-39$ and $\geq 40$ ).

The introduction of new steroid-sparing treatments has resulted in changing patterns of steroid prescription for IBD. ${ }^{38}$ To control for this, the 12-year study period was divided into three periods of 4 years to adjust for the impact of era of UC diagnosis on our outcome measure. Era 1 covered the period from 1 January 2005 to 31 December 2008, era 2 from 1 January 2009 to 31 December 2012 and era 3 from 01 January 2013 to 31 December 2016.

\section{Statistical analysis}

Baseline characteristics of the treatment groups were summarised using frequencies and percentages.

We compared the proportion of patients meeting the definition of corticosteroid dependency over the 3-year period in each treatment group using the $\chi^{2}$ test.

We used a logistic regression model to estimate the OR of developing corticosteroid dependency within the first 3 years of UC diagnosis given TCA and SSRI use, adjusting for sex, age at diagnosis, era of diagnosis. We adjusted the analysis for clustering effects to account for differences in prescribing patterns between contributing primary care practices.
We considered a $p$ value of less than or equal to 0.05 to be statistically significant. All analyses were performed using STATA V.16 (Statacorp LP).

\section{RESULTS}

Over the study period of January 2005 to December 2016, we identified 6373 individuals with incident UC who had at least 3 years of follow-up. Five thousand two hundred and thirty $(82 \%)$ had no prescriptions for either SSRIs or TCAs. Five thousand four hundred and sixty-four $(85.7 \%)$ had no prescriptions for SSRIs and were classed as 'SSRI nonusers', 627 (9.8\%) were 'intermittent SSRI users' and 282 (4.4\%) were 'continuous SSRI users' (table 1). Of the 6373 individuals with UC $246(3.9 \%)$ were 'intermittent TCA users' and $63(1 \%)$ were 'continuous TCA users' (table 2).

Patients with 'continuous' and 'intermittent' SSRI treatment were more likely to be women and smokers compared with 'non-users' (table 1). 2.5\% of the 'non-users', $43.2 \%$ of the 'intermittent SSRI users' and $47.5 \%$ of 'continuous SSRI users' had prior SSRI treatment, respectively in the 6 months before IBD diagnosis.

\section{SSRIs and steroid dependency}

The proportion of individuals with UC who developed corticosteroid dependency within 3 years was similar in

Table 2 Baseline characteristics of ulcerative colitis patients by tricyclic antidepressant exposure status

\begin{tabular}{|c|c|c|c|}
\hline & $\begin{array}{l}\text { TCA } \\
\text { non-users* } \\
n=6064\end{array}$ & $\begin{array}{l}\text { TCA } \\
\text { intermittent } \\
\text { users }^{*} n=246\end{array}$ & $\begin{array}{l}\text { TCA } \\
\text { continuous } \\
\text { users }^{\star} n=63\end{array}$ \\
\hline Male sex & $3351(55 \%)$ & $112(46 \%)$ & $26(41 \%)$ \\
\hline \multicolumn{4}{|c|}{ Age at diagnosis } \\
\hline$<17$ years & $197(3 \%)$ & $0(0 \%)$ & $1(2 \%)$ \\
\hline $17-40$ years & $1778(29 \%)$ & $77(31 \%)$ & $14(22 \%)$ \\
\hline$>40$ years & $4089(67 \%)$ & $169(69 \%)$ & $48(76 \%)$ \\
\hline \multicolumn{4}{|l|}{ Era of diagnosis } \\
\hline 2005-2008 & $2970(46 \%)$ & $112(46 \%)$ & $33(52 \%)$ \\
\hline 2009-2012 & $2379(39 \%)$ & $98(40 \%)$ & $22(35 \%)$ \\
\hline 2013-2016 & $895(15 \%)$ & $36(15 \%)$ & $8(13 \%)$ \\
\hline Smoker & 517 (9\%) & $28(11 \%)$ & $7(11 \%)$ \\
\hline \multicolumn{4}{|l|}{ SSRI use } \\
\hline Non-users & $5230(86 \%)$ & $190(77 \%)$ & $44(70 \%)$ \\
\hline $\begin{array}{l}\text { Intermittent } \\
\text { users }\end{array}$ & $566(9 \%)$ & $50(20 \%)$ & $11(17 \%)$ \\
\hline $\begin{array}{l}\text { Continuous } \\
\text { users }\end{array}$ & $268(4 \%)$ & $6(2 \%)$ & $8(13 \%)$ \\
\hline
\end{tabular}

${ }^{*}$ Non-users defined as patients with no TCA prescriptions in first 3 years of diagnosis.

†Intermittent users defined as patients who received at least one TCA prescriptions within the first 3 years of diagnosis but were not continuous users.

$\ddagger$ Continuous users defined as patients with consecutive TCA prescriptions for first 3 years after diagnosis where the interval between TCA prescription $<90$ days.

SSRI, serotonin selective reuptake inhibitor; TCA, tricyclic antidepressant. 
intermittent SSRI users and non-SSRI users (14.8\% vs $13.6 \%, \mathrm{p}=0.38$ ). However significantly more 'continuous SSRI users' developed corticosteroid dependency than non-SSRI users $(18.8 \%$ vs $13.6 \%, \mathrm{p}=0.01)$.

Intermittent SSRI use was associated with a similar adjusted risk of corticosteroid dependency compared with non-SSRI users (OR 1.19, 95\% CI 0.95 to 1.50 ). However, continuous SSRI use was associated with a significantly higher adjusted risk of developing corticosteroid dependency (OR 1.62, 95\% CI 1.15 to 2.27, table 3) compared with non-SSRI users.

\section{TCAs and steroid dependency}

The proportion of individuals with UC who developed corticosteroid dependency within 3 years was similar in intermittent TCA users and non-TCA users $(14.6 \%$ vs $13.8 \%, \mathrm{p}=0.71)$. However, significantly more continuous TCA users developed corticosteroid dependency than non-TCA users $(23.8 \%$ vs $13.8 \%, \mathrm{p}=0.02)$.

Intermittent TCA use was associated with a similar adjusted risk of corticosteroid dependency compared with non-TCA users (OR 1.14, 95\% CI 0.78 to 1.66 ). However, continuous TCA use was associated with a significantly higher adjusted risk of developing corticosteroid dependency (OR 2.02, 95\% CI 1.07 to 3.81-table 3) compared with non-TCA users.

\section{DISCUSSION}

\section{Key findings}

In this large nationally representative cross-sectional study of over 6000 patients with UC, we demonstrated continuous SSRI and TCA use are both associated with a significantly increased risk of corticosteroid dependency. Our findings indicate that concurrent use of ADM in routine clinical practice identifies a population of patients with UC requiring more intensive medical therapy.

\section{Findings in relation to other studies}

We report a prevalence of ADM use of $23.1 \%$ among patients with UC in this nationally representative cohort. This is in keeping with previous studies which report a prevalence of ADM use of 24\%-28\%. ${ }^{20} 3940$ Our findings suggest that ADM use in routine clinical practice is associated with a more severe disease course in UC, manifest as an increased risk of corticosteroid dependency.

Research investigating the impact of ADMs on outcomes in IBD is limited and reported findings are mixed and conflicting. Some studies have suggested ADM use may be associated with reduced disease activity in IBD. ${ }^{41} \mathrm{~A}$ study of 28 patients with UC examined steroid use in the year before and the year after ADM use. ${ }^{6}$ Among patients who had received an ADM—steroid prescriptions, disease relapses and endoscopic procedures were significantly less frequent in the year after treatment with ADM.

A retrospective cohort study examined clinical outcomes in patients with IBD given their exposure to ADMs. ${ }^{40}$ The authors found a lower adjusted incidence of initiating corticosteroids during periods of ADM exposure compared with non-exposure. The disparity with our findings is likely because we chose not to adjust for treatment with an ADM before $\mathrm{UC}$ diagnosis because of significant collinearity between this and ADM use after diagnosis.

To date, one randomised controlled trial has been conducted assessing the impact of ADMs on disease activity in patients with UC. Daghaghzadeh et al randomised 44 patients with depression and either CD or UC, to either

Table 3 Logistic regression for risk of corticosteroid dependency within 3 years of diagnosis among patients with UC

\begin{tabular}{|c|c|c|c|c|}
\hline & \multicolumn{2}{|c|}{ Unadjusted $n=6373$} & \multicolumn{2}{|c|}{ Adjusted $n=6373$} \\
\hline & OR & $95 \% \mathrm{Cl}$ & OR & $95 \% \mathrm{Cl}$ \\
\hline \multicolumn{5}{|l|}{ Sex } \\
\hline Female & 1 & - & 1 & - \\
\hline Male & 1.25 & 1.09 to 1.44 & 1.29 & 1.12 to 1.48 \\
\hline \multicolumn{5}{|c|}{ Age at diagnosis } \\
\hline$<17$ & 2.15 & 1.54 to 2.99 & 2.15 & 1.54 to 3.01 \\
\hline $17-40$ & 1 & - & 1 & - \\
\hline$>40$ & 0.74 & 0.63 to 0.86 & 0.72 & 0.61 to 0.84 \\
\hline \multicolumn{5}{|c|}{ Era of diagnosis } \\
\hline 2005-2008 & 1 & - & 1 & - \\
\hline 2009-2012 & 0.99 & 0.84 to 1.16 & 0.97 & 0.82 to 1.14 \\
\hline 2013-2016 & 0.85 & 0.68 to 1.06 & 0.81 & 0.65 to 1.01 \\
\hline \multicolumn{5}{|l|}{ Smoking status } \\
\hline $\begin{array}{l}\text { Non- } \\
\text { Smoker }\end{array}$ & 1 & - & 1 & - \\
\hline Smoker & 0.90 & 0.79 to 1.03 & 0.89 & 0.78 to 1.01 \\
\hline \multicolumn{5}{|l|}{ TCA exposure* } \\
\hline Non-users & 1 & - & 1 & - \\
\hline $\begin{array}{l}\text { Intermittent } \\
\text { users }\end{array}$ & 1.07 & 0.74 to 1.55 & 1.14 & 0.78 to 1.66 \\
\hline $\begin{array}{l}\text { Continuous } \\
\text { users }\end{array}$ & 1.95 & 1.06 to 3.60 & 2.02 & 1.07 to 3.81 \\
\hline \multicolumn{5}{|c|}{ SSRI exposure† } \\
\hline Non-users & 1 & - & 1 & - \\
\hline $\begin{array}{l}\text { Intermittent } \\
\text { users }\end{array}$ & 1.11 & 0.88 to 1.39 & 1.19 & 0.95 to 1.50 \\
\hline $\begin{array}{l}\text { Continuous } \\
\text { users }\end{array}$ & 1.47 & 1.06 to 2.05 & 1.62 & 1.15 to 2.27 \\
\hline
\end{tabular}

Statistically significant results in bold.

*Non-users defined as patients with no TCA prescriptions in first 3 years of diagnosis. Intermittent users defined as patients who received at least one TCA prescriptions within the first 3 years of diagnosis but were not continuous users. Continuous users defined as patients with consecutive TCA prescriptions for first 3 years after diagnosis where the interval between TCA prescription $<90$ days. †Non-users defined as patients with no SSRI prescriptions in first 3 years of diagnosis. Intermittent users defined as patients who received at least one SSRI prescriptions within the first 3 years of diagnosis but were not continuous users. Continuous users defined as patients with consecutive SSRI prescriptions for first 3 years after diagnosis where the interval between antidepressant medication prescription $<90$ days.

SSRI, selective serotonin reuptake inhibitor; TCA, tricyclic antidepressant; UC, ulcerative colitis. 
12 weeks of duloxetine or placebo. ${ }^{8}$ Those in the treatment arm reported experiencing significantly fewer symptoms, though this may have represented a reduction in functional gastrointestinal symptoms rather than reduced organic disease activity. ${ }^{42}{ }^{43}$ A study by Sexton $e t$ $a l$ supports this, finding that 'perceived stress' is associated with IBD symptoms but not intestinal inflammation as determined by faecal calprotectin measurement. ${ }^{44}$

Chojnacki et al conducted a non-randomised trial which found a reduction in Mayo Clinic Disease Activity Index scores among individuals treated with tianeptine compared with placebo. Fewer patients in the treatment arm had a relapse of their UC than those on placebo $(0 / 30$ vs $3 / 30$, respectively) however given the small numbers in both arms these findings should be interpreted with caution. ${ }^{10}$

Although there is some evidence from previous studies that both $\mathrm{TCAs}^{24}$ and SSRIs ${ }^{3}$ may ameliorate colitis, our findings suggest this may be outweighed by the association between a more severe UC disease process and depression. ${ }^{185}$ It is possible a bi-directional relationship between psychological comorbidity and IBD disease activity exists. A recent study by Gracie et al found baseline anxiety, but not depression, in quiescent IBD was associated with a subsequent increased need for steroids, and importantly also observed active IBD, as defined by a raised calprotectin, was associated with onset of anxiety, highlighting the bi-directional interaction. ${ }^{46}$

\section{Strengths and limitations}

In this large population-based study, we used a validated research database representative of the general UK population making it less likely to be affected by referral centre bias. We modelled both our treatment groups and outcome on previously published work from CPRD, and our regression models included adjustments for demographic and clinical covariates.

There are limitations to the study design. CPRD contains data on all prescriptions in primary care. However, it does not capture corticosteroid prescriptions in secondary care meaning our study may have underestimated corticosteroid use in some individuals.

Steroid dependency is a surrogate marker of disease severity. However, data on mucosal inflammation, disease extent and inflammatory markers such as faecal calprotectin were not available for analysis. It is therefore possible some corticosteroids prescriptions were inappropriate, as individuals may have had functional symptoms rather than active UC. Although objective markers of disease activity were not available for analysis in this study, it is likely the clinicians prescribing corticosteroids would have had access to at least some of these. Some individuals may have developed corticosteroid dependency as a consequence of failure to escalate to thiopurine or biological therapies, which we were unable to account for in this study. ${ }^{47}$

We extracted prescription data for TCA and SSRI antidepressant medications. We acknowledge a small minority of patients may have been prescribed alternative ADMs not captured in this study. We did not analyse individual dose ranges of $\mathrm{ADMs}$ although we have previously established $83 \%$ of amitriptyline prescriptions in this population are issued at a dose of $30 \mathrm{mg}$ or less per day. We also developed a model based on published research to define patients considered as having 'intermittent' and 'continuous' ADM use, allowing us to explore a dose-response relationship. ${ }^{34}$

We were not able to identify the specific indication for ADM prescription. However, in a cohort of primary care patients in the UK, contemporary with our study period, the indication for the majority of ADM prescriptions was either depression or anxiety. ${ }^{48}$ Given a significant proportion of TCA prescriptions were for low dose amitriptyline, it is likely in many cases TCAs were prescribed for other indications such as chronic pain, as higher doses are indicated for depression and anxiety. Both SSRIs and TCAs can cause gastrointestinal symptoms as side-effects, which could be interpreted as symptoms of UC, potentially resulting in inappropriate corticosteroid prescription. ${ }^{49}$ We also recognise the possibility that corticosteroid use itself may increase the risk of depression among patients with IBD,$^{50}$ though their impact in this respect is usually short lived. ${ }^{51}$

\section{Implications}

Our findings indicate an association between ADM use and worse clinical outcomes in UC as evidenced by increased corticosteroid dependency, underscoring the possible bi-directional relationship between psychiatric comorbidity and poorer outcomes in UC. It is well established that individuals with active UC are more likely to develop depression, but the converse may also be possible. ${ }^{18}$ This study reinforces the notion that management of common comorbid mental health disorders needs to be integral to the management of patients with UC.

The use of ADMs in IBD is supported by both national and international guidelines, ${ }^{52}{ }^{53}$ although the evidence base is limited and further work to evaluate treatment approaches for depression in IBD is required.

Gastroenterologists are reportedly poor at recognising concurrent psychiatric illnesses among their patients, ${ }^{54}$ despite guidelines encouraging doctors to screen for these conditions. ${ }^{53}$ Continuous ADM use among patients with UC can be considered a surrogate marker for worse disease outcomes. Patients receiving regular ADM prescriptions should be recognised as individuals potentially at risk of a more aggressive disease course, as well as those who may require additional psychological support.

Prescribers also need to be aware patients' adherence to medications for UC may be reduced among individuals receiving medications for depression..$^{55}$ Further prospective studies are needed to assess the temporal relationship between mood disorders and IBD disease exacerbations. The neuro-immunomodulatory action of $\mathrm{ADM}$ on IBD disease activity using validated measures of 
inflammation is yet to be determined, although the forthcoming MODULATE trial may address the use of amitriptyline in stable UC.

\section{CONCLUSIONS}

$\mathrm{ADM}$ use in routine clinical practice identifies a population of patients with UC with worse clinical outcomes manifest as increased rates of corticosteroid dependency. Clinicians should consider ADM use a flag for potentially worse clinical outcomes in the natural history of UC.

\author{
Author affiliations \\ ${ }^{1}$ Imperial College London Department of Primary Care and Public Health, London, \\ UK \\ ${ }^{2}$ Department Gastroenterology, St George's University Hospitals NHS Foundation \\ Trust, London, UK \\ ${ }^{3}$ The POP-IBD study group, London, UK \\ ${ }^{4}$ Gastroenterology, Royal Surrey County Hospital NHS Foundation Trust, Guildford, \\ UK \\ ${ }^{5}$ Primary Care and Public Health, Imperial College, London, UK \\ ${ }^{6}$ Dr Foster Unit, School of Public Health, Faculty of Medicine, Imperial College, \\ London, UK \\ ${ }^{7}$ Department of Primary Care \& Population Health, University College London, \\ London, UK \\ ${ }^{8}$ Division of Academic Psychiatry, Institute of Psychiatry Psychology and \\ Neuroscience, London, UK \\ ${ }^{9}$ South London and Maudsley Mental Health NHS Trust, London, UK \\ ${ }^{10}$ Institute for Infection and Immunity, St George's University of London, London, UK
}

Contributors $\mathrm{JB}$ and $\mathrm{CA}$ are joint first authors having contributed equally to this manuscript. RCGP will act as the guarantor for the article. All authors contributed to the concept and design of the study. JB, CA, SS, RCGP, IP, AB and MH designed the study and all authors contributed to preparation and editing of the final manuscript. All authors have approved the final manuscript including the authorship list.

Funding This work was supported by the Living with IBD Research Programme at Crohn's \& Colitis UK (grant number: SP2018/3). RCGP received support by a Wellcome Trust Institute Strategic Support Fund (ISSF) grant. SS is funded by the National Institute for Health Research (NIHR) School for Public Health Research (SPHR) and NIHR Northwest London Applied Research Collaboration (ARC). The School for Public Health Imperial College London is also grateful for support from the Imperial NIHR Biomedical Research Centre. MH Is funded by the NIHR Biomedical Research Centre at the Maudsley and is an NIHR Senior Investigator. The Dr Foster Unit at Imperial is affiliated with the National Institute of Health Research (NIHR) Imperial Patient Safety Translational Research Centre. The NIHR Imperial Patient Safety Translational Centre is a partnership between the Imperial College Healthcare NHS Trust and Imperial College London. The Dr Foster Unit at Imperial College are grateful for support from the NIHR Biomedical Research Centre funding scheme. $A B$ and the Unit are additionally funded by grants from NIHR and the British Heart Foundation.

Disclaimer This funding source had no role in the design or execution of this study or in the analysis and interpretation of the data. The views expressed are those of the authors and not necessarily those of Crohn's \& Colitis UK, NHS, the NIHR or the Department of Health and Social Care.

Competing interests None declared.

Patient consent for publication Not required.

Ethics approval Ethical and scientific approval for the use of CPRD for our study was granted by the Independent Scientific Advisory Committee (ISAC Protocol number: 15_018R).

Provenance and peer review Not commissioned; externally peer reviewed.

Data availability statement Data may be obtained from a third party and are not publicly available. Data are held by a third party, namely the Clinical Practice Research Datalink, and may be obtained upon reasonable request.

Open access This is an open access article distributed in accordance with the Creative Commons Attribution 4.0 Unported (CC BY 4.0) license, which permits others to copy, redistribute, remix, transform and build upon this work for any purpose, provided the original work is properly cited, a link to the licence is given, and indication of whether changes were made. See: https://creativecommons.org/ licenses/by/4.0/.

\section{ORCID iDs}

Jonathan Blackwell http://orcid.org/0000-0003-4278-3720

Christopher Alexakis http://orcid.org/0000-0002-5487-0752

Sonia Saxena http://orcid.org/0000-0003-3787-2083

Hanna Creese http://orcid.org/0000-0003-0431-7753

Alex Bottle http://orcid.org/0000-0001-9978-2011

Irene Petersen http://orcid.org/0000-0002-0037-7524

Matthew Hotopf http://orcid.org/0000-0002-3980-4466

Richard C G Pollok http://orcid.org/0000-0001-6452-6763

\section{REFERENCES}

1 Gracie DJ, Hamlin PJ, Ford AC. The influence of the brain-gut axis in inflammatory bowel disease and possible implications for treatment. Lancet Gastroenterol Hepatol 2019;4:632-42.

2 Ghia J-E, Blennerhassett P, Deng Y, et al. Reactivation of inflammatory bowel disease in a mouse model of depression. Gastroenterology 2009;136:2280-8.

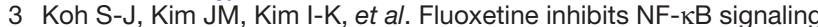
in intestinal epithelial cells and ameliorates experimental colitis and colitis-associated colon cancer in mice. Am J Physiol Gastrointest Liver Physiol 2011;301:G9-19.

4 Fattahian E, Hajhashemi V, Rabbani M, et al. Anti-Inflammatory effect of amitriptyline on ulcerative colitis in normal and reserpine-induced depressed rats. Iran J Pharm Res 2016;15:125-37.

5 Minaiyan M, Hajhashemi V, Rabbani M, et al. Effect of venlafaxine on experimental colitis in normal and reserpinised depressed rats. Res Pharm Sci 2015;10:295-306.

6 Goodhand JR, Greig FIS, Koodun Y, et al. Do antidepressants influence the disease course in inflammatory bowel disease? A retrospective case-matched observational study. Inflamm Bowel Dis 2012;18:1232-9.

7 Mikocka-Walus A, Hughes PA, Bampton P, et al. Fluoxetine for maintenance of remission and to improve quality of life in patients with Crohn's disease: a pilot randomized placebo-controlled trial. $J$ Crohns Colitis 2017;11:509-14.

8 Daghaghzadeh $\mathrm{H}$, Naji F, Afshar $\mathrm{H}$, et al. Efficacy of duloxetine add on in treatment of inflammatory bowel disease patients: a doubleblind controlled study. J Res Med Sci 2015;20:595-601.

9 Yanartas O, Kani HT, Bicakci E, et al. The effects of psychiatric treatment on depression, anxiety, quality of life, and sexual dysfunction in patients with inflammatory bowel disease. Neuropsychiatr Dis Treat 2016;12:673-83.

10 Chojnacki C, Walecka-Kapica E, Klupińska G, et al. [Evaluation of the influence of tianeptine on the psychosomatic status of patients with ulcerative colitis in remission]. Pol Merkur Lekarski 2011;31:92-6.

11 Mikocka-Walus A, Prady SL, Pollok J, et al. Adjuvant therapy with antidepressants for the management of inflammatory bowel disease. Cochrane Database Syst Rev 2019;4:CD012680.

12 Keefer L, Kane SV. Considering the bidirectional pathways between depression and IBD: recommendations for comprehensive IBD care. Gastroenterol Hepatol 2017;13:164-9.

13 Johnson JD, Campisi J, Sharkey CM, et al. Catecholamines mediate stress-induced increases in peripheral and central inflammatory cytokines. Neuroscience 2005;135:1295-307.

14 Chen C, Brown DR, Xie Y, et al. Catecholamines modulate Escherichia coli 0157:H7 adherence to murine cecal mucosa. Shock 2003;20:183-8.

15 Kelly JR, Kennedy PJ, Cryan JF, et al. Breaking down the barriers: the gut microbiome, intestinal permeability and stress-related psychiatric disorders. Front Cell Neurosci 2015;9:392.

16 Mawdsley JE, Rampton DS. Psychological stress in IBD: new insights into pathogenic and therapeutic implications. Gut 2005;54:1481-91.

17 Cohen S, Janicki-Deverts D, Doyle WJ, et al. Chronic stress, glucocorticoid receptor resistance, inflammation, and disease risk. Proc Natl Acad Sci U S A 2012;109:5995-9.

18 Mikocka-Walus A, Knowles SR, Keefer L, et al. Controversies revisited: a systematic review of the comorbidity of depression and anxiety with inflammatory bowel diseases. Inflamm Bowel Dis 2016;22:752-62.

19 Haapamäki J, Tanskanen A, Roine RP, et al. Medication use among inflammatory bowel disease patients: excessive consumption of antidepressants and analgesics. Scand J Gastroenterol 2013;48:42-50 
20 Mikocka-Walus AA, Gordon AL, Stewart BJ, et al. The role of antidepressants in the management of inflammatory bowel disease (IBD): a short report on a clinical case-note audit. J Psychosom Res 2012;72:165-7.

21 Mikocka-Walus A, Andrews JM. Attitudes towards antidepressants among people living with inflammatory bowel disease: an online Australia-wide survey. J Crohns Colitis 2014;8:296-303.

22 Marrie RA, Walld R, Bolton JM, et al. Psychiatric comorbidity increases mortality in immune-mediated inflammatory diseases. Gen Hosp Psychiatry 2018;53:65-72.

23 Narula N, Pinto-Sanchez MI, Calo NC, et al. Anxiety but not depression predicts poor outcomes in inflammatory bowel disease. Inflamm Bowel Dis 2019;25:1255-61.

24 Mittermaier C, Dejaco C, Waldhoer T, et al. Impact of depressive mood on relapse in patients with inflammatory bowel disease: a prospective 18-month follow-up study. Psychosom Med 2004:66:79-84.

25 Mikocka-Walus A, Pittet V, Rossel J-B, et al. Symptoms of depression and anxiety are independently associated with clinical recurrence of inflammatory bowel disease. Clin Gastroenterol Hepatol 2016;14:829-35.

26 Alexakis C, Kumar S, Saxena S, et al. Systematic review with meta-analysis: the impact of a depressive state on disease course in adult inflammatory bowel disease. Aliment Pharmacol Ther 2017;46:225-35.

27 Harbord M, Eliakim R, Bettenworth D, et al. Third European evidence-based consensus on diagnosis and management of ulcerative colitis. Part 2: current management. J Crohn's Colitis 2017;11:769-84

28 Lamb CA, Kennedy NA, Raine T, et al. British Society of gastroenterology consensus guidelines on the management of inflammatory bowel disease in adults. Gut 2019;68:gutjnl-2019-318484.

29 Blackwell J, Saxena S, Jayasooriya N, et al. Prevalence and duration of gastrointestinal symptoms before diagnosis of inflammatory bowel disease and predictors of timely specialist review: a population-based study. J Crohns Colitis 2020. doi:10.1093/eccojcc/jjaa146. [Epub ahead of print: 15 Jul 2020].

30 Herrett E, Gallagher AM, Bhaskaran K, et al. Data resource profile: clinical practice research Datalink (CPRD). Int J Epidemiol 2015;44:827-36.

31 Lewis JD, Brensinger C, Bilker WB, et al. Validity and completeness of the general practice research database for studies of inflammatory bowel disease. Pharmacoepidemiol Drug Saf 2002;11:211-8.

32 John A, McGregor J, Fone D, et al. Case-finding for common mental disorders of anxiety and depression in primary care: an external validation of routinely collected data. BMC Med Inform Decis Mak 2016;16:1-10

33 Ilyas S, Moncrieff J. Trends in prescriptions and costs of drugs for mental disorders in England, 1998-2010. Br J Psychiatry 2012;200:393-8.

34 Chollet J, Saragoussi D, Clay E, et al. A clinical research practice Datalink analysis of antidepressant treatment patterns and health care costs in generalized anxiety disorder. Value in Health 2013;16:1133-9.

35 Kalkan İsmail Hakkı, Dağlı Ülkü, Kekilli M, et al. Clinical course and predictors of total colectomy in ulcerative colitis; a referral center experience from turkey. Turk J Gastroenterol 2015;26:25-30.

36 Van Assche G, Dignass A, Panes J, Reinisch W, et al. The second European evidence-based consensus on the diagnosis and management of Crohn's disease: definitions and diagnosis. J Crohns Colitis 2010;4:7-27.
37 Lakatos PL, David G, Pandur T, et al. Ibd in the elderly population: results from a population-based study in Western Hungary, 19772008. J Crohns Colitis 2011;5:5-13.

38 Chhaya V, Saxena S, Cecil E, et al. Steroid dependency and trends in prescribing for inflammatory bowel disease - a 20-year national population-based study. Aliment Pharmacol Ther 2016;44:482-94.

39 Buckley JP, Kappelman MD, Allen JK, et al. The burden of comedication among patients with inflammatory bowel disease. Inflamm Bowel Dis 2013;19:2725-36.

40 Kristensen MS, Kjærulff TM, Ersbøll AK, et al. The influence of antidepressants on the disease course among patients with Crohn's disease and ulcerative Colitis-A Danish nationwide register-based cohort study. Inflamm Bowel Dis 2019;25:886-93.

41 Macer BJD, Prady SL, Mikocka-Walus A. Antidepressants in inflammatory bowel disease: a systematic review. Inflamm Bowel Dis 2017;23:534-50.

42 Halpin SJ, Ford AC. Prevalence of symptoms meeting criteria for irritable bowel syndrome in inflammatory bowel disease: systematic review and meta-analysis. Am J Gastroenterol 2012;107:1474-82.

43 Teruel C, Garrido E, Mesonero F. Diagnosis and management of functional symptoms in inflammatory bowel disease in remission. World J Gastrointest Pharmacol Ther 2016;7:78-90.

44 Sexton KA, Walker JR, Graff LA, a SK, a GL, et al. Evidence of bidirectional associations between perceived stress and symptom activity: a prospective longitudinal investigation in inflammatory bowel disease. Inflamm Bowel Dis 2017;23:473-83.

45 Kochar B, Barnes EL, Long MD, et al. Depression is associated with more aggressive inflammatory bowel disease. Am J Gastroenterol 2018;113:1-6.

46 Gracie DJ, Guthrie EA, Hamlin PJ, et al. Bi-directionality of braingut interactions in patients with inflammatory bowel disease. Gastroenterology 2018;154:1635-46.

47 Selinger CP, Parkes GC, Bassi A, et al. A multi-centre audit of excess steroid use in 1176 patients with inflammatory bowel disease. Aliment Pharmacol Ther 2017;46:964-73.

48 Petty DR, House A, Knapp P, et al. Prevalence, duration and indications for prescribing of antidepressants in primary care. Age Ageing 2006;35:523-6.

49 Cartwright C, Gibson K, Read J, et al. Long-term antidepressant use: patient perspectives of benefits and adverse effects. Patient Prefer Adherence 2016;10:1401-7.

50 Brooks AJ, Rowse G, Ryder A, et al. Systematic review: psychological morbidity in young people with inflammatory bowel disease - risk factors and impacts. Aliment Pharmacol Ther 2016:44:3-15.

51 Clark JG, Srinath AI, Youk AO, et al. Predictors of depression in youth with Crohn disease. J Pediatr Gastroenterol Nutr 2014;58:569-73.

52 National Institude of Clinical Excellence. Depression in adults with a chronic physical health problem: recognition and management: CG91, 2009.

53 Van Assche G, Dignass A, Bokemeyer B, et al. Second European evidence-based consensus on the diagnosis and management of ulcerative colitis Part 3: special situations. J Crohns Colitis 2013;7:1-33.

54 Janmohamed N, Steinhart AH. Measuring severity of anxiety and depression in patients with inflammatory bowel disease: low concordance between patients and male Gastroenterologists. Inflamm Bowel Dis 2017;23:1168-73.

55 Severs M, Mangen M-JJ, Fidder $\mathrm{HH}$, et al. Clinical predictors of future nonadherence in inflammatory bowel disease. Inflamm Bowel Dis 2017;23:1568-76. 